\title{
Effects of Atrial Natriuretic Peptide on Rat Ventricular Fibroblasts During Differentiation Into Myofibroblasts
}

\author{
M. MOUBARAK ${ }^{1,2}$, C. MAGAUD ${ }^{2}$, Y. SALIBA ${ }^{1}$, A. CHATELIER ${ }^{2}$, P. BOIS ${ }^{2}$, J.F. FAIVRE $^{2 *}$, \\ N. FARÈS ${ }^{1^{*}}$ \\ * These authors contributed equally to this work.
}

${ }^{1}$ Laboratoire de Recherche en Physiologie et Physiopathologie, Pôle Technologie Santé, Faculté de Médecine, Université Saint Joseph, Beyrouth, Liban, ${ }^{2}$ ERL CNRS 7368, Université de Poitiers, Poitiers, France

Received June 6, 2014

Accepted September 26, 2014

On-line December 3, 2014

\begin{abstract}
Summary
Atrial natriuretic peptide antifibrotic properties are mainly described in cardiac myocytes or in induced cardiac myofibroblasts (Angiotensin II or TGF- $\beta$ induced differentiation). In the present work, we investigate the effects of ANP/NPRA/cGMP system in modulating rat cardiac fibroblasts function. Cardiac fibroblasts were isolated from adult Wistar male rats and cultured in the presence of serum in order to induce fibroblasts differentiation. Cultures were then treated with ANP $(1 \mu \mathrm{M})$, 8-Br-cGMP $(100 \mu \mathrm{M})$ or IBMX $(100 \mu \mathrm{M})$, a non-specific phosphodiesterases inhibitor. ANP significantly decreased proliferation rate and collagen secretion. Its effect was mimicked by the CGMP analog, while combining ANP with 8-Br-cGMP did not lead to additional effects. Moreover intracellular cGMP levels were elevated when cells were incubated with ANP confirming that ANP intracellular pathway is mediated by cGMP. Additionally, immunoblotting and immunofluorescence were used to confirm the presence of guanylyl cyclase specific natriuretic peptide receptors $A$ and $B$. Finally we scanned specific cGMP dependent PDEs via RT-qPCR, and noticed that inhibiting all PDEs led to an important decrease in proliferation rate. Effect of ANP became more prominent after 10 culture days, confirming the importance of ANP in fibroblasts to myofibroblasts differentiation. Uncovering cellular aspects of ANP/NPRA/CGMP signaling system provided more elements to help understand cardiac fibrotic process.
\end{abstract}

\section{Key words}

ANP • Fibroblast differentiation • Myofibroblast • cGMP • Cardiac fibrosis

\section{Corresponding author}

N. Farès, Laboratoire de Recherche en Physiologie et Physiopathologie, Pôle Technologie Santé, Faculté de Médecine, Université Saint Joseph, rue de Damas, B.P. 11-5076, Riad el Solh, Beyrouth 1107 2180, Liban. Fax: + 9611421 023. E-mail: nassim.fares@usj.edu.lb

\section{Introduction}

Cardiac fibroblasts $(\mathrm{CF})$ are the most abundant cell type in the adult mammalian heart (Camelliti et al. 2005). They play a critical role in normal myocardial structure and function (Manabe et al. 2002, Benamer et al. 2009). Under pathological conditions, cardiac fibroblasts gain the ability to differentiate into myofibroblats (MyoFb). While the principal role of myofibroblasts is to repair tissue injury, their persistent activation results in a maladaptive response, leading to cardiac fibrosis and consequently cardiac dysfunction (Kong et al. 2013). MyoFb are characterized by increased expression of many extracellular matrix (ECM) markers such as alpha smooth muscle actin ( $\alpha$-SMA), collagen, fibronectin, and fibroblast growth factor-2 (Banerjee et al. 2006, Souders et al. 2009). They also express high levels of pro-inflammatory molecules and matrix metalloproteinases (Santiago et al. 2010). Since collagen is a major determinant of myocardial structural integrity, its disproportionate increase in the heart leads to cardiac fibrosis (van Nieuwenhoven and Turner 2013). 
Parthasarathy et al. (2013) reported that atrial natriuretic peptide (ANP) decreased both collagen secretion and synthesis.

Atrial natriuretic peptide is a cardiac hormone primarily stored within atrial granules. It reaches the circulation in response to cardiac volume overload inducing vasodilation and enhancing natriuresis, diuresis, and plasma shift (Rubattu et al. 2008, Arjamaa 2014). At the molecular and cellular levels, the effects of ANP are primarily mediated through the guanylyl cyclase (GC) activity of natriuretic peptide receptors NPRs (especially NPR-A) and the releasing of cyclic GMP (cGMP) (Potter et al. 2006). cGMP is involved in a myriad of cellular functions and is produced by two main types of GCs that differ in their cellular localization and specific ligands activation (Tsai and Kass 2009, Francis et al. 2010). While plasma membrane-bound $\mathrm{GC}$ is activated by natriuretic peptides, cytosolic-soluble GC is activated by nitric oxide (Fischmeister et al. 2005). Phosphodiesterase (PDE) subtypes regulate distinct cellular functions by selectively degrading different cAMP and cGMP pools (Levy 2013, Lu et al. 2013); therefore they play crucial roles in regulating the amplitude and duration of cyclic nucleotide signaling (Qvigstad et al. 2010). Whereas some of these studies have exposed the involvement of ANP/NPR-A signaling system in the regulation of ECM collagen remodeling in cardiac fibroblasts, the downstream of signaling pathways regulating collagen production during the differentiation process of $\mathrm{CF}$ to $\mathrm{MyoFb}$ is yet unclear, and the cellular mechanisms underlying natriuretic peptide cGMP-dependent receptor activity are not well understood.

The aim of our study was to further investigate the ANP/NPR-A/cGMP system in serum-stimulated cultured adult rat cardiac myofibroblasts, for better understanding of cardiac fibrogenesis signaling process.

\section{Materials and Methods}

\section{Animals}

Wistar Strain male albino rats weighing 200$300 \mathrm{~g}$ were procured from the "Centre d'Elevage R. Janvier" (Le Genest-Saint Isle, France). The animals were housed in cages under proper environmental conditions, were fed ordinary rat chow and had free access to tap water. The experiments were conducted according to the Guiding Principles in the Care and Use of Animals approved by the Council of the American Physiological Society and were in adherence to the Guide for the Care and Use of Laboratory Animals published by the US National Institute of Health (NIH Publication no. 85-23, revised 1996) and according to the European Parliament Directive 2010/63/EU.

\section{Isolation and culture of adult rat ventricular fibroblasts}

Cardiac fibroblasts were isolated from adult rat and maintained in primary culture as previously described (Benamer et al. 2009). Briefly, rats were anesthetized with Ketamine (RotexMedica, $75 \mathrm{mg} / \mathrm{kg}$ ) and Xylazine (Interchemie, $10 \mathrm{mg} / \mathrm{kg}$ ). The heart was quickly removed and transferred to Tyrode's solution, containing (in $\mathrm{mM}$ ): $140 \mathrm{NaCl}, 5.4 \mathrm{KCl}, 1.8 \mathrm{CaCl}_{2}, 1.8 \mathrm{MgCl}_{2}, 10 \mathrm{HEPES}$, 10 glucose, $\mathrm{pH}$ 7.4. Ventricles were isolated and dissected in $\mathrm{Ca}^{2+}$-free Krebs solution containing (in $\mathrm{mM}$ ): $35 \mathrm{NaCl}, 7.75 \mathrm{KCl}, 20 \mathrm{Na}_{2} \mathrm{HPO}_{4}, 25 \mathrm{NaHCO}_{3}$, $1.18 \mathrm{KH}_{2} \mathrm{PO}_{4}, 10$ HEPES, 10 Glucose, 70 Sucrose $\mathrm{pH} 7.4$, supplemented with $30 \mathrm{mM}$ 2,3-butanedione 2-monoxime (BDM) and $0.5 \mathrm{mM}$ EGTA. Ventricules were digested by two successive enzymatic digestion steps. The first pre-digestion bath $(15 \mathrm{~min})$ contained collagenase type $\mathrm{V}(165.1 \mathrm{U} / \mathrm{ml})$ and protease type XXIV (4.62 U/ml) (Sigma-Aldrich) while the second bath (10 min) contained only collagenase $(157 \mathrm{U} / \mathrm{ml})$. The remaining tissue parts and cells were then recovered, and a step of gentle stirring was applied in a modified Tyrode's solution (in $\mathrm{mM}$ ): $130 \mathrm{NaCl}, 4.8 \mathrm{KCl}$, $1.2 \mathrm{KH}_{2} \mathrm{PO}_{4}, 25$ HEPES, 5 glucose, pH 7.4, supplemented with $2 \%$ BSA and $0.15 \mathrm{mM}$ EGTA. Cardiomyocytes were discarded after the first centrifugation (500 rpm, $10 \mathrm{~min})$, then fibroblasts collected after the second one (2000 rpm, $10 \mathrm{~min}$ ) were resuspended in DMEM (Biowhittaker) containing 10\% FBS (Lonza), $1 \%$ penicillin/streptomycin and $1 \%$ insulin. The culture medium was replaced with fresh medium every 2 days. This method resulted in optimized fibroblast cell cultures that were not contaminated by endothelial and/or smooth muscle cells as controlled by immunolabeling studies reported in a previous study (Benamer et al. 2009).

\section{Chemicals}

Atrial natriuretic peptide, 3-(4,5dimethylthiazol-2-yl)-2,5-diphenyl tetrazolium bromide (MTT), 8-bromoguanosine 3',5'-cyclic monophosphate (8-Br-cGMP), 3-isobutyl-1-methylxanthine (IBMX) and the monoclonal $\beta$-actin antibody (A2228) were purchased from Sigma Chemical Co. Rat specific polyclonal natriuretic peptide receptor A (ab14356) and B (ab14357) 
antibodies were purchased from Abcam.

\section{MTT cell proliferation assay}

This technique is based on the transformation of 3-(4,5-dimethylthiazol-2-yl)-2,5-diphenyl tetrazolium bromide to an insoluble formazan salt by active mitochondria (Mosmann 1983). Ventricular fibroblasts were cultured in 96-well plates (seeded at 20000 cells per well) and grown for 12 days in medium alone or in medium supplemented with different chemicals: ANP, 8$\mathrm{Br}$ cGMP and IBMX+ANP. The test was applied every 2 days from day 4 until day 12. A concentration of $0.5 \mathrm{mg} / \mathrm{ml}$ of MTT was added to each well and the plates were incubated for $4 \mathrm{~h}$ at $37^{\circ} \mathrm{C}$. Formazan crystals were then dissolved in dimethyl sulfoxide (100 $\mu \mathrm{l} / \mathrm{well})$. Formazan was quantified on a spectrophotometer at $570 \mathrm{~nm}$ (in triplicate).

\section{Enzyme-linked immunosorbent assay (ELISA) for c GMP}

Cells were cultured in 6-well plates (seeded at 800000 cells/well) for 12 days with different treatments: ANP, 8-Br-cGMP and IBMX+ANP. The medium was aspirated, and $1 \mathrm{ml}$ of cold PBS was added to each well and the plate was frozen at $-80^{\circ} \mathrm{C}$. The plates where then unfrozen on ice, the cells were scraped and mixed with 1 volume of cold $\mathrm{HCl}(300 \mu \mathrm{l} /$ well $)$ by vortex. After 5 min of incubation at room temperature, lysate was centrifuged at $4500 \mathrm{rpm}$ for $15 \mathrm{~min}$ and the pellet was removed. The supernatant was used to assess the level of cGMP which was measured after acetylation using the cyclic GMP ELISA kit (Abcam).

\section{Collagen measurements by SIRCOL collagen kit assay}

The SIRCOL collagen assay (Biocolor) was used to evaluate total collagen quantity in cell culture medium supernatants. Sirius Red $(1 \mathrm{ml})$, an anionic dye that reacts specifically with (Gly-X-Y)n tripeptide in the triple-helix sequence of mammalian collagens under assay conditions, was added to $100 \mu \mathrm{l}$ of supernatant and incubated under gentle rotation for $30 \mathrm{~min}$ at room temperature. After centrifugation for $10 \mathrm{~min}$ at 13000 rpm, the collagen-bound dye was dissolved with $1 \mathrm{ml}$ of $0.5 \mathrm{M} \mathrm{NaOH}$, and the absorbance was measured at $555 \mathrm{~nm}$ (in duplicate).

\section{Western blotting}

Fibroblasts cultured in 6 well plates (seeded at 1 million cells/well) were washed with ice-cold PBS and lysed by scraping the cells into $100 \mu \mathrm{l}$ of lysis buffer (in mmol/1: Tris- $\mathrm{HCl}$ 50, NaCl 150, EDTA 5, $0.05 \%$ Igepal, $1 \%$ deoxycholic acid, $1 \%$ Triton X-100, $0.1 \%$ SDS) containing protease inhibitors (Protease Inhibitor Cocktail, Sigma). Cell lysates were then incubated for $30 \mathrm{~min}$ on ice, sonicated then centrifuged at $14000 \mathrm{rpm}$ for $10 \mathrm{~min}$ at $4{ }^{\circ} \mathrm{C}$. Protein quantities were measured using DC protein assay (Biorad) with BSA as a reference. Soluble cell lysates were denatured for $1 \mathrm{~h}$ at $37^{\circ} \mathrm{C}$ in Laemmli $2 \mathrm{X}$ buffer (in mmol/l) Tris-HCl 126, SDS $4 \%$, glycerol $20 \%$, bromophenol blue $0.02 \%$, betamercaptoethanol $5 \%$. Protein samples $(50 \mu \mathrm{g})$ obtained from the myofibroblasts, were separated using $8 \%$ SDSPAGE and then transferred to nitrocellulose membranes (Bio-Rad apparatus). Membranes were blocked for $1 \mathrm{~h}$ in TBS-Tween blocking solution (in mmol/1: Tris- $\mathrm{HCl} 100$, $\mathrm{NaCl} 150$ and Tween-20 0.1\%) with $5 \%$ BSA and then probed overnight with gentle agitation at $4{ }^{\circ} \mathrm{C}$ with primary antibodies (1:5000 for NPRs and 1:10000 for beta-actin). Membranes were then washed three times for $5 \mathrm{~min}$ incubated for $1 \mathrm{~h}$ at room temperature with specific anti-rabbit or anti-goat horseradish peroxidase-conjugated secondary antibodies (1:10000, Interchim). Membranes were revealed with ECL chemiluminescent substrate (Amersham). Signal intensities of bands in the immunoblots were quantified using ImageJ analysis software.

\section{Immunofluorescence staining}

Fibroblasts were cultured on coverslips and grown in DMEM for immunofluorescence (IF). Cells were fixed with paraformaldehyde (PFA) for $10 \mathrm{~min}$, permeabilized by a 10 min incubation in PBS containing $0.5 \%$ Triton X-100, and blocked in PBS containing $5 \%$ BSA. Samples were then incubated overnight at $4{ }^{\circ} \mathrm{C}$ with primary antibodies anti-NPRA and anti-NPRB $(1 / 100)$ in PBS containing $1 \%$ BSA and $0.1 \%$ Triton X-100, after which they were incubated for $1 \mathrm{~h}$ at room temperature with the fluorophore-conjugated secondary antibody Alexa Fluor 555 in the same solution (1/200) and with TOPRO 3 (diluted 1/1000) to label cell nuclei. Coverslips were rinsed and mounted using fluorescence mounting medium (Vectashield, Vector Laboratories) on glass microscope slides and examined by confocal microscopy.

\section{Data analysis and statistics}

Results are presented as mean \pm SEM. Statistical analysis was performed with Student t-test or one-way analysis of variance (ANOVA) with Bonferroni's post hoc tests for multiple comparisons using Origin 8.0 
(Microcal Software, Inc.). The results are expressed as mean \pm SEM and a $p$ value of less than 0.05 was considered as statistically significant.

\section{Results}

Functional effects of ANP on cell proliferation and collagen secretion

Fibroblasts are known to be involved in cardiac remodeling process, notably by their ability to proliferate, to differentiate into myofibroblasts and to secrete extracellular matrix proteins, including collagen. We have reported previously that fibroblasts are able to differentiate spontaneously into myofibroblasts after 6 to 8 days in culture. In the present study, we evaluated the effect of ANP on the properties of cultured fibroblasts. Cells were incubated in either normal medium or in medium supplemented with ANP at a concentration of $1 \mu \mathrm{M}$. Fibroblast cell number was estimated by MTT test at different times following cell isolation, i.e. after 6,8 , 10 and 12 days of culture. As illustrated in Figure 1A, the number of fibroblasts increased with culture duration in control condition, as previously reported (Benamer et al. 2009). ANP was able to reduce cell proliferation relative to control from 8 days of culture and this effect became significant from 10 days of culture. In parallel, collagen secretion was measured by Sircol test in the culture medium at the same times and under the same experimental conditions. Results are illustrated in Figure $1 \mathrm{~B}$, and show that ANP significantly reduced collagen secretion from 8 days of culture. These results suggest that ANP decreases cardiac fibroblast proliferation and secretion properties after differentiation into myofibroblasts, confirming antifibrotic effect of natriuretic peptide in our experimental conditions. In another set of experiments, we found that ANP $1 \mu \mathrm{M}$ was able to reduce cell proliferation and collagen secretion increase induced by $0.1 \mu \mathrm{M}$ Angiotensin II (data not shown).

Natriuretic peptide receptors identification in cultured rat cardiac myofibroblasts

To confirm the presence of the main receptors commonly reported to account for ANP effects, we evaluated expression of guanylyl cyclase type receptors NPRA and NPRB in our cellular model. Western blot experiments were performed after 12 days of culture $(n=4)$. Left panel of Figure 2A illustrates immunoblots showing the expression of both isoforms NPRA and
NPRB. Right panel of Figure 2A depicts average intensity measured for NPRA and NPRB proteins, relative to $\beta$-actin on 4 independent experiments. Unspecific binding was checked on HeLa cells, which confirms the absence of NPRA expression on this type of cells. On the other hand, confocal microscopy with separate immunofluorescence staining was performed under permeabilized conditions with NPRA and NPRB antibodies. Cells incubated with these specific antibodies revealed positive staining for both isoforms (Fig. 2B).
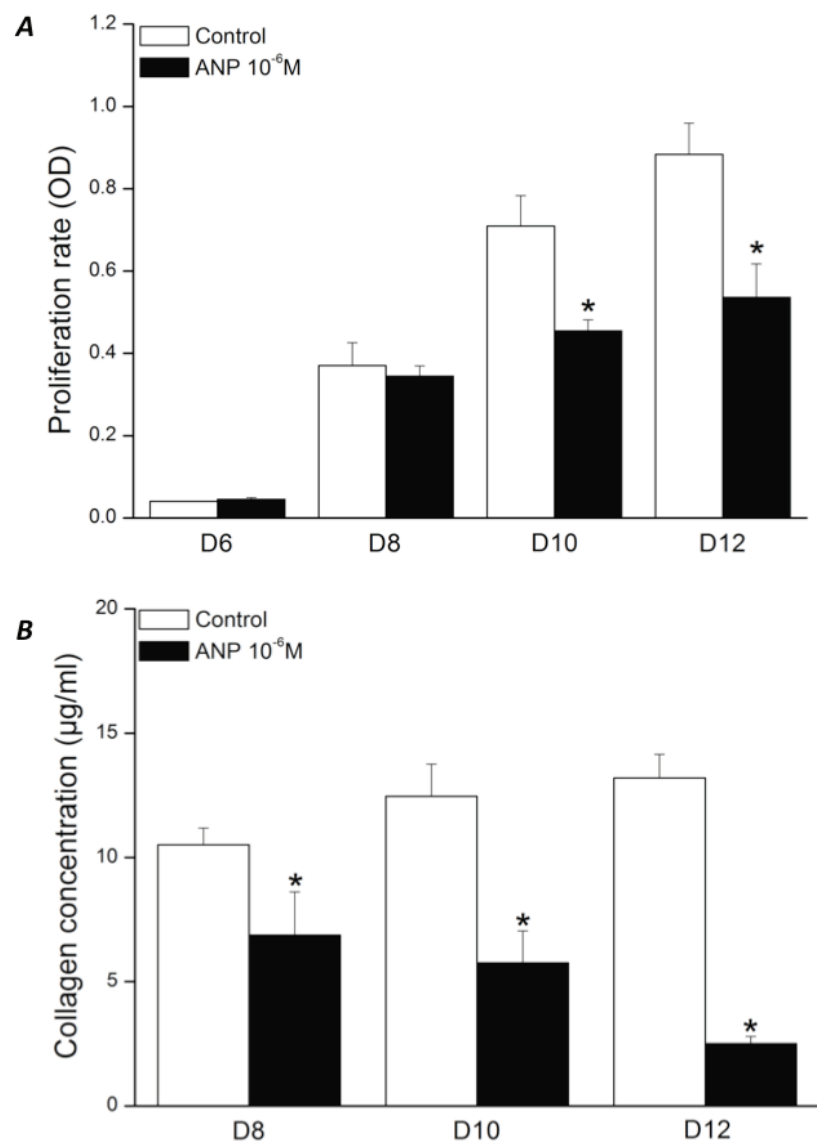

Fig. 1. Effects of ANP on proliferation and collagen secretion in rat cardiac fibroblasts. (A): The effects of ANP were evaluated on ventricular fibroblast proliferation by MTT test from 6 to 12 days of culture every $48 h(n=5)$. (B): The secretion of collagen was measured from 8 to 12 days $(n=5)$ in the absence (open bars) and the presence of ANP $\left(10^{-6} \mathrm{M}\right)$ (solid bars). ${ }^{*} \mathrm{p}<0.05$ vs Control

Functional effects of cGMP on cell proliferation and collagen secretion

Because NPRA and NPRB receptors are known to be linked to guanylyl cyclase, we checked whether the effects previously obtained with ANP could be reproduced by cGMP. For this purpose, we investigated the effect of 8-bromo-cGMP, a membrane-permeant and 

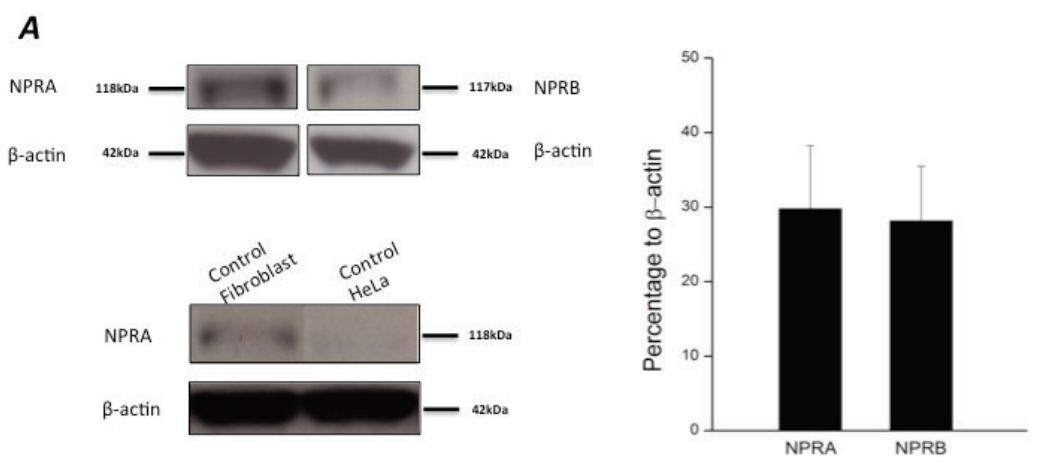

Fig. 2. Expression of type $A$ and type $B$ of natriuretic peptide receptors in cardiac myofibroblasts after 12 days of culture. (A): Western blots were performed on protein extracts obtained using NPRA, NPRB and $\beta$-actin antibodies. Blotting analysis on right panel illustrates the result of 4 experiments. Non-specific binding was assessed on HeLa cells. (B): Positive immunofluorescence staining with NPRA (left panel, red labeling) and NPRB (right panel, red labeling) antibodies on cardiac myofibroblasts. This result is typical for that obtained in 4 independent experiments. Scale bars: $50 \mu \mathrm{m}$

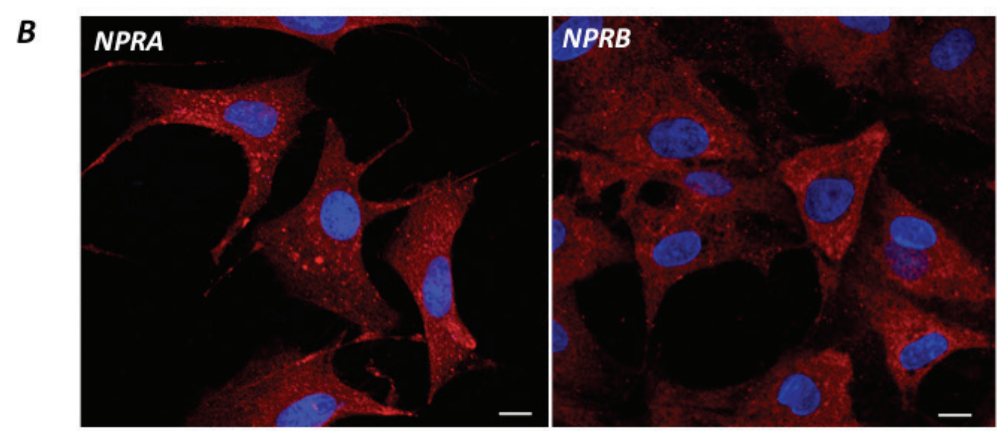

metabolically resistant cGMP analog, on cardiac fibroblasts cultures. Again, cell proliferation and collagen secretion were recorded as markers of fibroblast function. As shown in Figure 3, 8-bromo-cGMP induced similar effect as previously obtained with ANP. Indeed, spontaneous cell proliferation increase was reduced by 8-bromo-cGMP as fibroblasts differentiate into myofibroblasts and this effect reached statistical significance from 10 days of culture. Interestingly, the simultaneous application of 8-bromo-cGMP and ANP did not lead to additional effects (Fig. 3B), suggesting that the intracellular pathway involved in the effects of both ligands is the same. Finally, we found that 8-bromocGMP was able to significantly reduce collagen secretion (Fig. 3C), an effect which resembles that previously obtained with ANP.

\section{Phosphodiesterases in rat cardiac myofibroblasts}

The results obtained so far suggest that ANP reduces fibroblast function through the activation of NPRA/NPRB receptors which increase intracellular cGMP levels. Our last set of experiments aimed at evaluating the influence of phosphodiesterases (PDEs) involved in cGMP degradation. The chosen phosphodiesterases are the known cGMP-dependent isoforms with the second messenger cGMP acting as a regulator and/or a substrate (Maurice et al. 2003, Lugnier 2006, Houslay et al. 2007, Omori and Kotera 2007, Miller and Yan 2010, Lee and Kass 2012).
$\boldsymbol{A}$

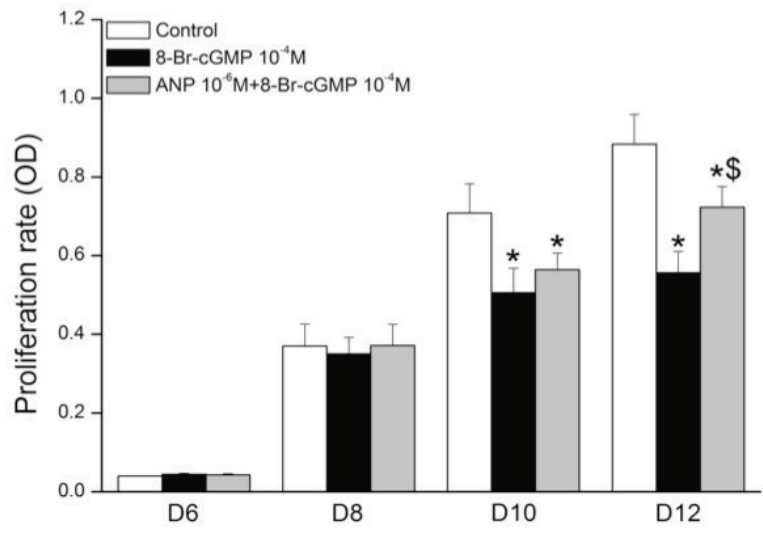

B

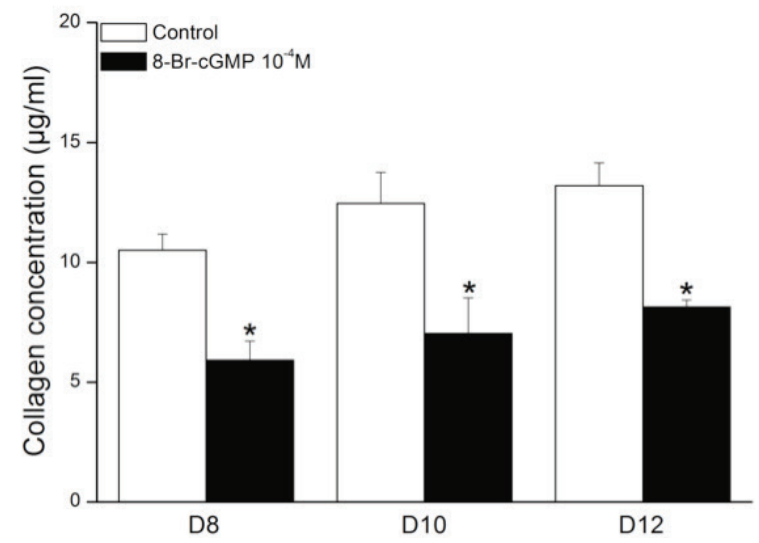

Fig. 3. Effects of 8-Br-cGMP on proliferation and collagen secretion in rat cardiac fibroblasts. The effects of $8-B r-c G M P$ and ANP plus 8-Br-cGMP (A) were evaluated on ventricular fibroblast proliferation by MTT test from 6 to 12 days of culture every $48 h(n=5)$. (B): The secretion of collagen was measured from 8 to 12 days $(n=5)$ in the absence (open bars) and the presence of 8 -Br-cGMP) (solid bars). ${ }^{*} \mathrm{p}<0.05$ vs Control, ${ }^{\$} \mathrm{p}<0.05$ vs 8 -Br-cGMP 


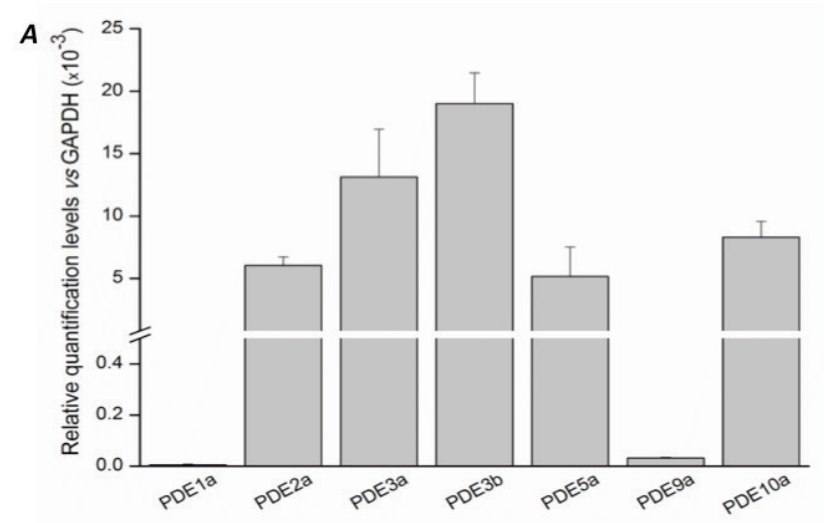

B

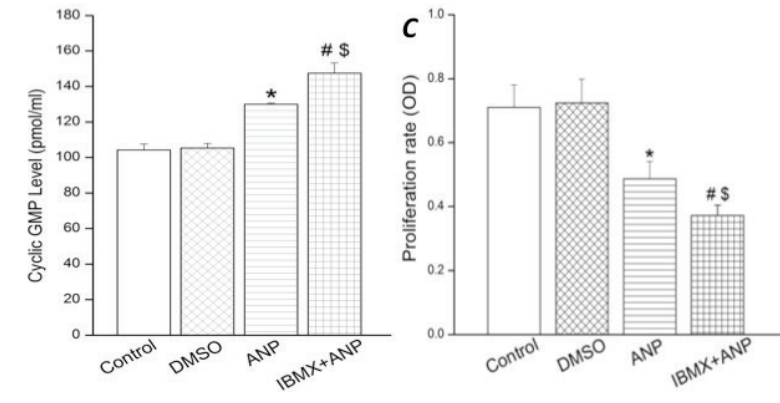

Fig. 4. Relative expression of cGMP-specific phosphodiesterase isoforms and effect of PDE inhibition in cardiac myofibroblasts. All experiments were performed after 12 days of culture. (A): Relative expression of CGMP-PDE isoforms evaluated by RT-qPCR using GAPDH as internal control $(n=3)$. (B and C): Intracellular concentration of cyclic GMP $(B, n=5)$ and myofibroblast cell number $(C, n=3)$ measured in the absence and in the presence of DMSO $(0.1 \%)$, ANP $\left(10^{-6} \mathrm{M}\right)$ and IBMX $\left(10^{-4} \mathrm{M}\right)+\operatorname{ANP}\left(10^{-6} \mathrm{M}\right) .{ }^{*} \mathrm{p}<0.05$ vs Control; ${ }^{*} \mathrm{p}<0.05$ vs DMSO and ${ }^{\$} \mathrm{p}<0.05$ vs ANP

First, we examined the expression profile of cGMP-PDEs using RT-qPCR in fibroblasts cultured during 12 days. The result illustrated in Figure 4A demonstrates that multiple cGMP-PDEs are expressed in cardiac myofibroblasts and may be involved in cGMP level modulation. In order to correlate ANP effects, PDE activity and cGMP level, intracellular cGMP concentration was measured using enzyme immunoassay in different experimental conditions. As illustrated in Figure 4B, DMSO $0.1 \%$ which was used at the same concentration to prepare IBMX solution, did not modify cGMP level. On the opposite, ANP $1 \mu \mathrm{M}$ resulted in an expected and significant increase in cGMP levels in comparison to control, strengthening the hypothesis that NPR receptors solicited by ANP are able to modulate intracellular cGMP concentration. When ANP was applied in the presence of IBMX, a potent and nonselective PDE inhibitor, intracellular cGMP concentration was further increased, suggesting that cGMP level is indeed balanced between guanylyl cyclase activity and
PDE-induced degradation. Accordingly, Figure 4C shows that ANP-induced decrease in myofibroblasts cell number relative to control after 12 days of culture was more pronounced in the presence of IBMX.

\section{Discussion}

In the present work, we report the effects of cardiac natriuretic peptides, especially ANP, in modulating rat cardiac fibroblasts differentiation. We demonstrate that ANP reduces cell proliferation and collagen secretion as fibroblasts differentiate into myofibroblasts. Both effects are mimicked by an increase of intracellular cGMP, suggesting the involvement of NPRA and/or NPRB receptors, which are equally expressed in cardiac myofibroblasts. Finally, we show that ANP effects are further increased by cGMP-PDE inhibition, strengthening the possible implication of cGMP in fibroblast and myofibroblast physiological regulation.

Our work shows, for the first time, the effects of ANP on cellular proliferation and collagen secretion during differentiation of cultured cardiac fibroblasts into myofibroblasts. ANP's anti-fibrotic effects gain statistical significance after 10 days of culture ( 1.5 fold decrease in proliferation and fivefold decrease in collagen secretion). These results revealed the importance of ANP effects not only on cardiac fibroblasts (Souders et al. 2009, Santiago et al. 2010), but also during fibroblasts to myofibroblasts differentiation. The fact that collagen secretion even decreased with culture duration in the presence of ANP whereas cell proliferation still increased suggests that ANP major effect is on differentiation more than on proliferation. ANP has been investigated in many works (Patel et al. 2005, Rubattu et al. 2008). Its antifibrotic properties are mainly described in cardiomyocytes (Potter 2011, Dickey et al. 2012, Volpe et al. 2014). The atrial natriuretic peptide and its receptor (NPRA) are able to shape the whole underlying signaling system by inducing various physiological effects in a cell specific or tissue specific manner. Studies have shown that ANP inhibited the proliferation of mouse mesangial cell by suppressing the phosphorylation of MAPKs (Tripathi and Pandey 2012) and fetal sheep cardiomyocyte proliferation by inhibiting ERK and AKT phosphorylation (O'Tierney et al. 2010). Moreover, our results show ANP effect passes through cGMP signaling according to many previous studies (Fischmeister et al. 2005, Castro et al. 2010). cGMP, mimicking ANP's effects, reflected an inhibitive 
response on cellular proliferation and a decrease in collagen secretion. This result has been demonstrated on collagen secretion levels with a different approach on freshly dissociated CFs (Parthasarathy et al. 2013). When combined with 8-Br-cGMP, we noticed that ANP's effects, especially on proliferation were not enhanced. This suggests that once intracellular pathway is saturated by cGMP, it can no further activate the ANP/NPRA system and therefore this system seems to be directly regulated by cGMP in rat cardiac myofibroblasts.

In parallel, the effects of ANP were enhanced and cGMP levels were increased in cardiac myofibroblasts, when IBMX was added to the culture media to non-selectively inhibit PDEs. This resulted in a strong inhibitory outcome on cellular proliferation (twofold decrease). Recent studies have shown that an increase in cGMP and specifically activation of the cGKI (GMP-dependent protein kinase I) inhibits the differentiation of cardiac fibroblasts into myofibroblasts, induced by TGF- $\beta$ or Angiotensin II (Patrucco et al. 2014).

Furthermore, scanning and quantifying cGMP dependent PDE isoenzymes was performed on 12 days serum induced myofibroblasts and reveal 5 different transcript expression. Expression of these specific PDEs seems to have a central role in modulating cGMP (Qvigstad et al. 2009, Vettel et al. 2014), thus modulating the ANP/NPRA system. Lu et al. (2013) quantified PDEs in TGF- $\beta$ induced cardiac myofibroblasts obtained from Sprague-Dawley rats, and their studies have showed that cAMP can prevent the CFs to myofibroblasts transformation and that increased cAMP levels can reverse the profibrotic myofibroblastic phenotype.

Finally we confirmed the presence of the guanalyl cyclase NP receptors by immunoblot and confocal microscopy in serum induced cardiac myofibroblats.

Recently, Bice et al. (2014) revealed the importance of cGMP as therapeutic agent in ischemic heart diseases. Moreover, Huntley et al. (2006, 2010) exposed the importance of BNP/cGMP interaction in the cardiac repair after myocardial infarction and his potential anti-proliferative effects in human cardiac fibroblasts. Based on these works, it would be interesting to study cGMP modulation in our cellular model, by determining the intracellular changes in cardiac fibrosis process via ERK1/2 (Sun et al. 2009) or GATA4 (Jankowski 2009, Glen et al. 2009) and their position in natriuretic peptides signaling pathway (especially ANP). Furthermore targeting specific PDEs, involved in cGMP homeostasis, can provide important information concerning the precise implicated isoforms in cardiac fibroblasts-myofibroblasts differentiation.

In conclusion, this study showed the important role of ANP/NPRA signaling in fibroblast to myofibroblast differentiation. cGMP and specific PDEs modulating cell proliferation, migration and differentiation provide new insights into better understanding cardiac fibrosis in pathogenic situations.

\section{Conflict of Interest}

There is no conflict of interest.

\section{Acknowledgements}

This work was funded by the Fondation de France and the Research Council of the Saint Joseph University Beirut, Lebanon.

\section{References}

ARJAMAA O: Physiology of natriuretic peptides: The volume overload hypothesis revisited. World J Cardiol 6: 4-7, 2014.

BANERJEE I, YEKKALA K, BORG TK, BAUDINO TA: Dynamic interactions between myocytes, fibroblasts and extracellular matrix. Ann N Y Acad Sci 1080: 76-84, 2006.

BENAMER N, MOHA OU MAATI H, DEMOLOMBE S, CANTEREAU A, DELWAIL A, BOIS P, BESCOND J, FAIVRE JF: Molecular and functional characterization of a new potassium conductance in mouse ventricular fibroblasts. J Mol Cell Cardiol 46: 508-517, 2009.

BICE JS, BURLEY DS, BAXTER GF: Novel approaches and opportunities for cardioprotective signaling through 3',5'cyclic guanosine monophosphate manipulation. J Cardiovasc Pharmacol Ther 19: 269-282, 2014.

CAMELLITI P, BORG TK, KOHL P: Structural and functional characterisation of cardiac fibroblasts. Cardiovasc Res 65: 40-51, 2005. 
CASTRO LR, SCHITTL J, FISCHMEISTER R: Feedback control through cGMP-dependent protein kinase contributes to differential regulation and compartmentation of cGMP in rat cardiac myocytes. Circ Res 107: 1232-1240, 2010.

DICKEY DM, DRIES DL, MARGULIES KB, POTTER LR: Guanylyl cyclase (GC)-A and GC-B activities in ventricles and cardiomyocytes from failed and non-failed human hearts: GC-A is inactive in the failed cardiomyocyte. J Mol Cell Cardiol 52: 727-732, 2012.

FISCHMEISTER R, CASTRO L, ABI-GERGES A, ROCHAIS F, VANDECASTEELE G: Species- and tissuedependent effects of NO and cyclic GMP on cardiac ion channels. Comp Biochem Physiol A Mol Integr Physiol 142: 136-143, 2005.

FRANCIS SH, BUSCH JL, CORBIN JD, SIBLEY D: cGMP-dependent protein kinases and cGMP phosphodiesterases in nitric oxide and cGMP action. Pharmacol Rev 62: 525-563, 2010.

GLENN DJ, RAHMUTULA D, NISHIMOTO M, LIANG F, GARDNER DG. Atrial natriuretic peptide suppresses endothelin gene expression and proliferation in cardiac fibroblasts through a GATA4-dependent mechanism. Cardiovasc Res 84: 209-217, 2009.

HOUSLAY MD, BAILLIE GS, MAURICE DH: cAMP-specific phosphodiesterase-4 enzymes in the cardiovascular system: a molecular toolbox for generating compartmentalized cAMP signaling. Circ Res 100: 950-966, 2007.

HUNTLEY BK, SANDBERG SM, NOSER JA, CATALIOTTI A, REDFIELD MM, MATSUDA Y, BURNETT JC: BNP-induced activation of cGMP in human cardiac fibroblasts: interactions with fibronectin and natriuretic peptide receptors. J Cell Physiol 209: 943-949, 2006.

HUNTLEY BK, ICHIKI T, SANGARALINGHAM SJ, CHEN HH, BURNETT JC: B-type natriuretic peptide and extracellular matrix protein interactions in human cardiac fibroblasts. J Cell Physiol 225: 251-255, 2010.

JANKOWSKI M: GATA4, a new regulator of cardiac fibroblasts, is sensitive to natriuretic peptides. Cardiovasc Res 84: 176-177, 2009.

LEE DI, KASS DA: Phosphodiesterases and cyclic GMP regulation in heart muscle. Physiology (Bethesda) 27: 248$258,2012$.

LEVY FO: Cardiac PDEs and crosstalk between cAMP and cGMP signalling pathways in the regulation of contractility. Naunyn Schmiedebergs Arch Pharmacol 386: 665-670, 2013.

LU D, AROONSAKOOL N, YOKOYAMA U, PATEL HH, INSEL PA: Increase in cellular cyclic AMP concentrations reverses the profibrogenic phenotype of cardiac myofibroblasts: a novel therapeutic approach for cardiac fibrosis. Mol Pharmacol 84: 787-793, 2013.

LUGNIER C: Cyclic nucleotide phosphodiesterase (PDE) superfamily: a new target for the development of specific therapeutic agents. Pharmacol Ther 109: 366-398, 2006.

MANABE I, SHINDO T, NAGAI R: Gene expression in fibroblasts and fibrosis: involvement in cardiac hypertrophy. Circ Res 91: 1103-1113, 2002.

MAURICE DH, PALMER D, TILLEY DG, DUNKERLEY HA, NETHERTON SJ, RAYMOND DR, ELBATARNY HS, JIMMO SL: Cyclic nucleotide phosphodiesterase activity, expression, and targeting in cells of the cardiovascular system. Mol Pharmacol 64: 533-546, 2003.

MILLER CL, YAN C: Targeting cyclic nucleotide phosphodiesterase in the heart: therapeutic implications. J Cardiovasc Transl Res 3: 507-515, 2010.

MOSMANN T: Rapid colorimetric assay for cellular growth and survival: application to proliferation and cytotoxicity assays. J Immunol Methods 65: 55-63, 1983.

O'TIERNEY PF, CHATTERGOON NN, LOUEY S, GIRAUD GD, THORNBURG KL: Atrial natriuretic peptide inhibits angiotensin II-stimulated proliferation in fetal cardiomyocytes. J Physiol 588: 2879-2889, 2010.

OMORI K, KOTERA J: Overview of PDEs and their regulation. Circ Res 100: 309-327, 2007.

PARTHASARATHY A, GOPI V, UMADEVI S, SIMNA A, SHEIK MJ, DIVYA H, VELLAICHAMY E: Suppression of atrial natriuretic peptide/natriuretic peptide receptor-A-mediated signaling upregulates angiotensin-IIinduced collagen synthesis in adult cardiac fibroblasts. Mol Cell Biochem 378: 217-228, 2013.

PATEL JB, VALENCIK ML, PRITCHETT AM, BURNETT JC, MCDONALD JA, REDFIELD MM: Cardiac-specific attenuation of natriuretic peptide A receptor activity accentuates adverse cardiac remodeling and mortality in response to pressure overload. Am J Physiol Heart Circ Physiol 289: H777-H784, 2005. 
PATRUCCO E, DOMES K, SBROGGIO M, BLAICH A, SCHLOSSMANN J, DESCH M, RYBALKIN SD, BEAVO JA, LUKOWSKI R, HOFMANN F: Roles of cGMP-dependent protein kinase I (cGKI) and PDE5 in the regulation of Ang II-induced cardiac hypertrophy and fibrosis. Proc Natl Acad Sci U S A 111: 12925-12929, 2014.

POTTER LR: Natriuretic peptide metabolism, clearance and degradation. FEBS J 278: 1808-1817, 2011.

POTTER LR, ABBEY-HOSCH S, DICKEY DM: Natriuretic peptides, their receptors, and cyclic guanosine monophosphate-dependent signaling functions. Endocr Rev 27: 47-72, 2006.

QVIGSTAD E, MOLTZAU LR, ARONSEN JM, NGUYEN CH, HOUGEN K, SJAASTAD I, LEVY FO, SKOMEDAL T, OSNES JB: Natriuretic peptides increase betal-adrenoceptor signalling in failing hearts through phosphodiesterase 3 inhibition. Cardiovasc Res 85: 763-772, 2010.

RUBATTU S, SCIARRETTA S, VALENTI V, STANZIONE R, VOLPE M: Natriuretic peptides: an update on bioactivity, potential therapeutic use, and implication in cardiovascular diseases. Am J Hypertens 21: 733-741, 2008.

SANTIAGO JJ, DANGERFIELD AL, RATTAN SG, BATHE KL, CUNNINGTON RH, RAIZMAN JE, BEDOSKY KM, FREED DH, KARDAMI E, DIXON IM: Cardiac fibroblast to myofibroblast differentiation in vivo and in vitro: expression of focal adhesion components in neonatal and adult rat ventricular myofibroblasts. Dev Dyn 239: 1573-1584, 2010.

SOUDERS CA, BOWERS SL, BAUDINO TA: Cardiac fibroblast: the renaissance cell. Circ Res 105: 1164-1176, 2009.

SUN Y, EICHELBAUM EJ, WANG H, VESELY DL: Cardiac hormones activate ERK 1/2 kinases in human fibroblasts. Horm Metab Res 41: 197-201, 2009.

TRIPATHI S, PANDEY KN: Guanylyl cyclase/natriuretic peptide receptor-A signaling antagonizes the vascular endothelial growth factor-stimulated MAPKs and downstream effectors AP-1 and CREB in mouse mesangial cells. Mol Cell Biochem 368: 47-59, 2012.

TSAI EJ, KASS DA: Cyclic GMP signaling in cardiovascular pathophysiology and therapeutics. Pharmacol Ther 122: 216-238, 2009.

VAN NIEUWENHOVEN FA, TURNER NA: The role of cardiac fibroblasts in the transition from inflammation to fibrosis following myocardial infarction. Vascul Pharmacol 58: 182-188, 2013.

VETTEL C, LÄMMLE S, EWENS S, CERVIRGEN C, EMONS J, ONGHERTH A, DEWENTER M, LINDNER D, WESTERMANN D, NIKOLAEV VO, LUTZ S, ZIMMERMANN WH, EL-ARMOUCHE A: PDE2-mediated cAMP hydrolysis accelerates cardiac fibroblast to myofibroblast conversion and is antagonized by exogenous activation of cGMP signaling pathways. Am J Physiol Heart Circ Physiol 306: H1246-H1252, 2014.

VOLPE M, RUBATTU S, BURNETT J: Natriuretic peptides in cardiovascular diseases: current use and perspectives. Eur Heart J 35: 419-425, 2014. 